\title{
Frequency and reasons for delayed treatment initiation after HIV diagnosis: cross-sectional study in Lahore, Pakistan
}

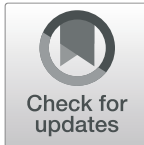

\author{
Hassan Ali ${ }^{1}$, Rubeena Zakar ${ }^{1}$, Khunsa Junaid ${ }^{1}$, Amjad Khan ${ }^{2}$ and Florian Fischer ${ }^{3,4^{*}}$
}

\begin{abstract}
Background: Well-timed initiation of HIV therapy enhances life expectancy, decreases mortality and morbidity, and inhibits the transmission of HIV and complications related to it. The purpose of the present survey is to investigate the frequency and reasons for delayed initiation of anti-retroviral therapy (ART) and to determine its relationship with various socio-demographic variables and HIV-related characteristics.

Methods: The analysis is based on a cross-sectional study involving 355 people living with HIV (diagnosed by PCR) who were more than 18 years of age and not receiving HIV therapy before enrolment at the HIV clinics of two selected tertiary-care teaching hospitals in Lahore, Pakistan. In this study, delayed initiation of ART was defined as not attending the HIV management centre or a clinic for ART within 3 months of a confirmed diagnosis. The participants were selected using a systematic probability sampling technique. Bivariate logistic regression was performed using a backward stepwise technique to establish the variables related to delayed onset of HIV therapy. Factors significant at $p \leq 0.20$ were considered for multivariate analysis, which was used to describe the association between independent factors and delayed initiation of treatment.
\end{abstract}

Results: Delayed onset of ART was observed in $28.5 \%$ of individuals. Factors such as no schooling (AOR $=5.92 ; 95 \% \mathrm{Cl}$ : $1.38-25.41 ; p=0.017$ ) and occasional household income ( $\mathrm{AOR}=3.88 ; 95 \% \mathrm{Cl}: 1.01-14.89 ; p=0.048$ ) were significantly associated with late onset of ART. Our research findings also indicated that the main reasons for late beginning of HIV therapy were: feeling healthy (45.5\%), did not have time to go to the HIV treatment centre (42.6\%), did not want to discuss HIV test result (37.6\%), and fear of stigma and discrimination within their community (35.6\%).

Conclusions: Late commencement of HIV therapy in Pakistan is common, and an improved connection is needed between identification of HIV and beginning of therapy. HIV management centres should counsel and monitor patients from the time of a positive HIV test result until they initiate therapy.

Keywords: HIV, Delayed initiation, ART, PCR

\footnotetext{
* Correspondence: florian.fischer1@charite.de; florian.fischer@rwu.de

${ }^{3}$ Institute of Public Health, Charité, Universitätsmedizin Berlin, Charitéplatz 1,

10117 Berlin, Germany

${ }^{4}$ Institute of Gerontological Health Services and Nursing Research,

Ravensburg-Weingarten University of Applied Sciences, Weingarten, Germany

Full list of author information is available at the end of the article
}

(c) The Author(s). 2021, corrected publication 2021. Open Access This article is licensed under a Creative Commons Attribution 4.0 International License, which permits use, sharing, adaptation, distribution and reproduction in any medium or format, as long as you give appropriate credit to the original author(s) and the source, provide a link to the Creative Commons licence, and indicate if changes were made. The images or other third party material in this article are included in the article's Creative Commons licence, unless indicated otherwise in a credit line to the material. If material is not included in the article's Creative Commons licence and your intended use is not permitted by statutory regulation or exceeds the permitted use, you will need to obtain permission directly from the copyright holder. To view a copy of this licence, visit http://creativecommons.org/ licenses/by/4.0/. The Creative Commons Public Domain Dedication waiver (http://creativecommons.org/publicdomain/zero/1. 0/) applies to the data made available in this article, unless otherwise stated in a credit line to the data. 


\section{Background}

The human immunodeficiency virus (HIV) still results in a substantial number of deaths every year due to acquired immunodeficiency syndrome (AIDS)-related illnesses. Globally, there are about 38 million people living with HIV (PLHIV), and approximately 690,000 individuals died from AIDS-related disorders in 2019 [1]. In 2019, about 190,000 PLHIV were present in Pakistan, with a prevalence of $0.1 \%$ in adults aged $15-49$ years [2].

Numerous socioeconomic factors, including poverty, lack of education, and unemployment, are likely to promote the transmission of HIV in Pakistan [3]. PLHIV exist in almost all population sub-groups. For example, HIV outbreaks comprising mainly male sex workers (MSWs) are expanding significantly in comparison with female sex workers (FSWs), revealing diversity in localized sex practices $[4,5]$. HIV outbreaks are rapidly increasing among intravenous drug users (IDUs). IDUs having sexual contacts with MSWs and transgendered individuals are the main reason for HIV escalation in many areas of Pakistan. As a consequence of this, Pakistan appears to be following the "Asian Epidemic Model" [5].

The majority of PLHIV who do not receive HIV treatment are reported to have a recognizable virus load in their bodily fluids, and, therefore, may spread the virus to their sexual partners. According to prevention policies related to HIV/AIDS, early detection and commencement of anti-retroviral treatment (ART) can remarkably reduce disease transmission [6-8]. Late commencement of ART results in increased admissions to hospital owing to opportunistic infections [6,7]. Timely initiation of ART and management of opportunistic infections will reduce mortality and morbidity $[7,8]$, and will prevent secondary transmission and HIV-associated complications. Therefore, it will result in enhanced health and life expectancy for PLHIV [8-11].

Ideally, ART should be started before the beginning of opportunistic infections. However, both in economically developed and developing nations, many PLHIV start HIV treatment late [12]. The primary reasons for the late onset of HIV treatment vary in relation to community and local traditions $[6,8]$. One of the reasons for late onset of HIV treatment is lack of awareness about the World Health Organization's (WHO) guidelines on the timing of ART [11]. According to WHO guidelines on HIV treatment, in order to prevent HIV transmission, early initiation of ART is recommended irrespective of CD4 count [13]. Nevertheless, in Pakistan the old guidelines are still followed for use of ART [14]. According to these guidelines, ART treatment can be initiated in all PLHIV presenting with clinical symptomatic disease or asymptomatic disease with total lymphocyte count (TLC) below $1200 / \mathrm{mm}^{3}$, if a CD4 assay is not available.
But in cases where a CD4 assay is available, ART will be started for WHO stage IV disease (when PLHIV develop AIDS) regardless of CD4 count, or WHO stage III disease (presence of symptoms due to opportunistic infections) with CD4 count below 350 cells $/ \mathrm{mm}^{3}$, or asymptomatic disease with CD4 count below 200 cells $/ \mathrm{mm}^{3}$ [14]. In Pakistan, only $10 \%$ of PLHIV are getting ART, and adherence to treatment is also very low [15].

Until now, evidence about the reasons for late onset of HIV treatment from economically developing countries outside the African continent has been lacking and there is no study available in Pakistan to address this issue. Therefore, the present study aims to identify the frequency and reasons for delayed initiation of HIV treatment in Pakistan and determine its association with sociodemographic variables and HIV-related characteristics.

\section{Methods}

\section{Study design}

The cross-sectional study was conducted between December 2017 and November 2018 in the HIV clinics of two hospitals in Lahore, Pakistan, which are the largest teaching hospitals in the public sector. These HIV clinics work under the administrative control of the Punjab AIDS Control Programme (PACP). The city of Lahore was selected for this research because of its diverse socio-demographic and economic profile. The Integrated Behaviour and Biological Survey 2011-2012 indicated a high prevalence of HIV in several cities in Pakistan. For example, in Lahore the HIV prevalence was $30.8 \%$ among people who inject drugs, 5.2\% among transgender (hijra) sex workers, $1.7 \%$ among male sex workers, and $0.5 \%$ among female sex workers [16]. Another reason for the selection of Lahore was that it is the capital of Punjab Province of Pakistan. Most of the HIV clinics in Punjab are situated in Lahore. Due to this, PLHIV across Punjab come to Lahore for their treatment.

Careful methodological and ethical considerations (such as informed consent, voluntary participation, privacy, confidentiality, and anonymity) are necessary when performing research on sensitive topics, particularly in countries like Pakistan. Considering this, data from PLHIV were collected at the HIV clinics of two selected teaching hospitals of Lahore. Pakistan is a traditionalist country, where performing research on sensitive issues like HIV requires careful consideration of ethical issues. HIV clinics are situated in teaching hospitals and interviews were carried out in these hospitals in a separate room attached to the HIV clinic where they could proceed without any interference from outsiders or family members of patients. In the Pakistani family set up, it is difficult to interview an HIV patient alone in a 
household setting. Additionally, the presence of others may prevent respondents from giving accurate information about their disease. There is also a real risk that the questions relating to HIV that are asked during the interview may offend relatives of the respondents.

Confidentiality, anonymity, and privacy for all study participants were guaranteed at all levels in this study. No identifying information about the patient, such as name, date of birth, telephone number, or address, was recorded. Verbal informed consent was taken from each patient before they enrolled in the study. The aim of the research was explained to the patients in detail. Patients were also informed about the possible risks/discomfort involved. The data collection was carried out in a comfortable environment in a separate room attached to the HIV clinic where patients had the opportunity to speak openly, and they also had the right to ask any question about the study. All aspects of data collection were carried out in accordance with the "Guidelines and Recommendations to Assure Good Epidemiologic Practice" developed by the German Society for Epidemiology [13].

\section{Respondents}

We recruited PLHIV, including both men and women who had not received HIV treatment before their enrolment at the HIV clinics of two selected hospitals in Lahore during the study period. Only HIV cases diagnosed by polymerase chain reaction (PCR) performed at a standardized laboratory were included. Patients younger than 18 years of age were not included in this study. Respondents who were not willing to participate and those who had started HIV treatment before enrolling at the HIV clinic of the selected hospitals were also excluded.

\section{Sampling}

Taking 30\% as the proportion of late onset of HIV treatment [12], the sample size was determined by applying the following formula, using a 5\% margin of error with a 95\% confidence interval (CI): $n=\frac{z^{2} p q}{d^{2}}$ [17]. With these parameters, the calculated sample size was 323, which was then increased by $10 \%$ to allow for an anticipated non-response rate. Therefore, in total, 355 PLHIV were included in this study.

The study respondents were selected using a systematic probability sampling technique. About 1000 new PLHIV visit the HIV clinic every year to start HIV treatment. Based on this information, we obtained the kvalue: $\mathrm{k}=\frac{N}{n}=\frac{(1000)}{(355)} \cong 3$. Based on this result, we took the second patient from the first group of three patients in the list as our first respondent, and then every third patient afterwards until we achieved the required sample size.

\section{Measures}

Data were assessed using a structured questionnaire (see Supplementary Appendix) in face-to-face interviews. The dependent variable was 'delay in initiation of HIV treatment'. The delay was defined according to the Centres for Disease Control and Prevention (CDC) directions as PLHIV who did not visit the HIV management centre for HIV treatment within 3 months of a confirmed diagnosis [18].

The independent variables encompassed sociodemographic factors (age, gender, religion [Muslim vs. Christian], place of residence, marital status, education, employment [employed vs. unemployed], and type of household income [permanent vs. occasional; where occasional household income refers to members of a household earning money occasionally or sometimes but not regularly. This occurs when they do not have a regular source of income. They work for daily wages and are sometimes unable to find work and do not earn money.]) and HIV-related characteristics (initial CD4 count, physical disability, and associated chronic diseases).

The questionnaire was developed on the basis of an extensive literature review $[6,9,11,12]$ and informal discussions with health experts managing HIV cases in Lahore. Questions were asked about HIV testing conducted due to an HIV-positive partner, due to the appearance of symptoms, as a routine test during pregnancy or before any surgery, or due to other reasons, in order to collect information regarding the reasons for HIV testing.

Furthermore, we assessed the reasons for delay in the initiation of HIV treatment. We asked questions in relation to different reasons, such as feeling healthy and judging the treatment as unnecessary, fear-related reasons (e.G. stigma and discrimination in the community or at the facility), time constraints making it difficult to visit the health facility, fear of the side effects of medication, insufficient knowledge about the HIV treatment facilities, inadequate accessibility, fear that HIV treatment is not confidential, concerns related to costs and having no health insurance, fear of detention or imprisonment, and perceptions regarding the low quality of service at the facility.

\section{Statistical analysis}

Data was analysed using SPSS version 26.0. After performing descriptive statistics, a chi-square test was applied. In addition, a bivariate logistic regression was performed using a backward stepwise technique to establish the variables related to delayed HIV treatment. Factors that were significant at $p<0.20$ were considered for the multivariate model [19]. The strengths of association were evaluated for factors related to late commencement of ART by 
means of adjusted odds ratios (AORs) with 95\% confidence intervals (CIs). The Hosmer-Lemeshow test was applied to analyse the goodness of fit for the final model [20].

\section{Results}

\section{Socio-demographic characteristics}

In total, 355 PLHIV (diagnosis confirmed by PCR test) were enrolled in this survey. The mean age of respondents was $31.75 \pm 8.53$ years. Among these, 261 (73.5\%) were men, 74 (20.9\%) were women and 20 (5.6\%) were transgender. With respect to religion, 339 (95.5\%) were Muslims and 16 (4.5\%) were Christians. Just under half, 166 (46.8\%), were residents of district Lahore. Most of the study respondents were living in urban areas (81.4\%) and married (60.3\%). About one third (32.4\%) had no formal schooling. About half of the study respondents (53.8\%) were employed. A little over half $(59.4 \%)$ had a regular source of income, whereas $144(40.6 \%)$ had only a temporary source of income (i.e., daily-waged jobs such as laborers, vendors, or salesmen) (Table 1).

\section{HIV-related characteristics}

About 72\% (254) of respondents had started ART within 3 months of their HIV diagnosis. However, this also implies that $28 \%$ of HIV-diagnosed individuals had started ART late. About half of the study respondents (49.9\%) had greater than 349 cells $/ \mathrm{mm}^{3}$ initial CD4 count. Most had no physical disability (82.5\%), while post-HIV and pre-HIV physical disability was present in 15.2 and $2.3 \%$, respectively. In terms of chronic diseases, $23.7 \%$ had hepatitis $\mathrm{C}, 15.5 \%$ had tuberculosis, $2.3 \%$ had diabetes, and $2.0 \%$ had hepatitis B (Table 2).

HIV testing was carried out due to the appearance of symptoms in $44.2 \%$ of cases, as part of routine follow-up in $23.4 \%$ of cases, due to a partner living with HIV in $20.0 \%$ of cases, as a routine test during pregnancy in $5.6 \%$ of cases, and just to check HIV status in $6.8 \%$ of cases (Fig. 1). Heterosexuality was reported by 122 (34.4\%) respondents as a risk factor for transmission of HIV, IDU by 120 (33.8\%) respondents, and homosexuality by $64(18.0 \%)$ respondents (Fig. 2$)$.

\section{Reasons for delayed onset of HIV treatment}

This study found that the main reasons for delayed initiation of ART were that patients felt healthy (45.5\%), did not have time to go to the HIV treatment centre (42.6\%), did not want to discuss their HIV test result (37.6\%), or were afraid of stigma and discrimination within their community (35.6\%) (Table 3).

\section{Bivariate analyses}

Our study results revealed that the socio-demographic variables of gender $\left(x^{2}=8.622 ; p=0.013\right)$, place of
Table 1 Socio-demographic characteristics of People living with HIV

\begin{tabular}{|c|c|c|}
\hline Variables & $n$ & $\%$ \\
\hline \multicolumn{3}{|l|}{ Age (in years) } \\
\hline $18-29$ & 162 & 45.6 \\
\hline $30-39$ & 124 & 34.9 \\
\hline 40 and above & 69 & 19.5 \\
\hline Mean \pm SD & $31.75 \pm 8.53$ & \\
\hline \multicolumn{3}{|l|}{ Gender } \\
\hline Male & 261 & 73.5 \\
\hline Female & 74 & 20.8 \\
\hline Transgender & 20 & 5.6 \\
\hline \multicolumn{3}{|l|}{ Religion } \\
\hline Muslim & 339 & 95.5 \\
\hline Christian & 16 & 4.5 \\
\hline \multicolumn{3}{|l|}{ District } \\
\hline Lahore & 166 & 46.8 \\
\hline Other & 189 & 53.2 \\
\hline \multicolumn{3}{|l|}{ Place of residence } \\
\hline Urban & 289 & 81.4 \\
\hline Rural & 66 & 18.6 \\
\hline \multicolumn{3}{|l|}{ Marital status } \\
\hline Unmarried & 119 & 33.5 \\
\hline Married & 214 & 60.3 \\
\hline Separated & 5 & 1.4 \\
\hline Divorced & 3 & 0.8 \\
\hline Widowed & 14 & 3.9 \\
\hline \multicolumn{3}{|l|}{ Educational level } \\
\hline No schooling & 115 & 32.4 \\
\hline Primary & 82 & 23.1 \\
\hline Secondary & 99 & 27.9 \\
\hline College & 39 & 11.0 \\
\hline University & 20 & 5.6 \\
\hline \multicolumn{3}{|l|}{ Employment status } \\
\hline Employed & 191 & 53.8 \\
\hline Unemployed & 164 & 46.2 \\
\hline \multicolumn{3}{|c|}{ Type of household income } \\
\hline Permanent income & 211 & 59.4 \\
\hline Occasional income & 144 & 40.6 \\
\hline
\end{tabular}

residence $\left(x^{2}=6.182 ; p=0.013\right)$, level of education $\left(x^{2}=\right.$ 20.580; $p<0.001)$, employment status $\left(x^{2}=7.161 ; p=\right.$ $0.007)$, and type of household income $\left(\chi^{2}=11.300 ; p=\right.$ 0.001 ) were significantly associated with late commencement of ART (Table 4). With respect to HIV-related characteristics, initial CD4 count $\left(x^{2}=6.652 ; p=0.036\right)$ was seen to be significantly associated with late commencement of ART (Table 5). 
Table 2 HIV-related and chronic disease related characteristics of people living with HIV

\begin{tabular}{lll}
\hline Variables & $\boldsymbol{n}$ & $\%$ \\
\hline Initiation of HIV treatment & & \\
$\quad$ Early ( $\leq 3$ months) & 254 & 71.5 \\
Delayed (>3 months) & 101 & 28.5 \\
Initial CD4 count (cells $/ \mathbf{m m}^{\mathbf{3}}$ ) & & \\
$\quad<200$ & 105 & 29.6 \\
200-349 & 76 & 21.4 \\
$>349$ & 174 & 49.0 \\
Median \pm IQR & $341 \pm 170$ & \\
Physical disability & & 82.5 \\
No & 293 & 2.3 \\
Pre-HIV & 8 & 15.2 \\
Post-HIV & 54 & \\
Any associated chronic disease & & 15.5 \\
Tuberculosis & 55 & 2.3 \\
Diabetes & 8 & 1.1 \\
Hypertension & 4 & 2.0 \\
Hepatitis B & 7 & 23.7 \\
Hepatitis C & 84 & \\
None & 197 & \\
\hline
\end{tabular}

\section{Logistic regression}

We applied a bivariate logistic regression to investigate the independent predictors related to late commencement of HIV treatment. All factors that were significant at $p<0.20$ in the bivariate regression analysis, consisting of district, place of residence, educational level, employment status, household income, initial CD4 count, reason for HIV testing, and any associated chronic disease, were included in a multivariable logistic regression model. After applying multivariate regression, the factors: district other than Lahore, living in a rural area, no formal schooling, occasional income, and greater than 349 cells $/ \mathrm{mm}^{3}$ initial CD4 count were seen to be significantly associated with delayed onset of HIV treatment $(p<0.05)$. After assessing the magnitudes of these associations, the results indicate that the respondents residing in district Lahore were less likely to be late for HIV treatment than residents of other districts (AOR $=0.52$; 95\% CI: $0.31-$ 0.87 ), and respondents residing in cities had 0.45 times lower chances of late HIV treatment initiation than those residing in rural areas $(\mathrm{AOR}=0.45 ; 95 \% \mathrm{CI}$ : 0.24-0.83). Respondents having no formal schooling were more likely to have delayed treatment initiation than university graduates $(\mathrm{AOR}=5.92 ; 95 \% \mathrm{CI}: 1.38-25.41)$. Respondents with a temporary source of income had greater chances of being late for HIV treatment than those with a permanent income $(\mathrm{AOR}=3.88 ; 95 \% \mathrm{CI}$ : $1.01-14.89)$. The study also concluded that respondents having a CD4 count of fewer than 200 cells $/ \mathrm{mm}^{3}$ had 0.48 times lower chances of being late for HIV treatment than those having a CD4 count of more than 349 cells $/ \mathrm{mm}^{3}$ (AOR $=0.48 ; 95 \%$ CI: $0.25-$ 0.93) (Table 6).

\section{Discussion}

This study has highlighted the frequency and reasons for delayed onset of HIV treatment in Lahore, Pakistan, and determined the relationship between delayed treatment onset and both socio-demographic and HIV-related characteristics. The characteristics of HIV-positive

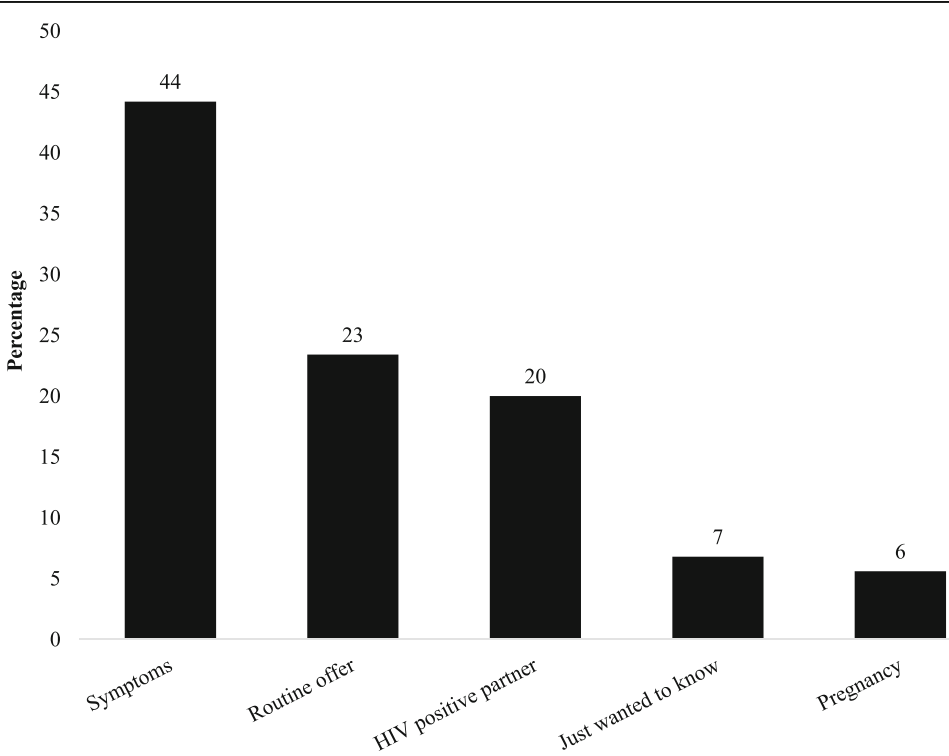

Fig. 1 Reason for HIV testing among people living with HIV $(N=355)$ 


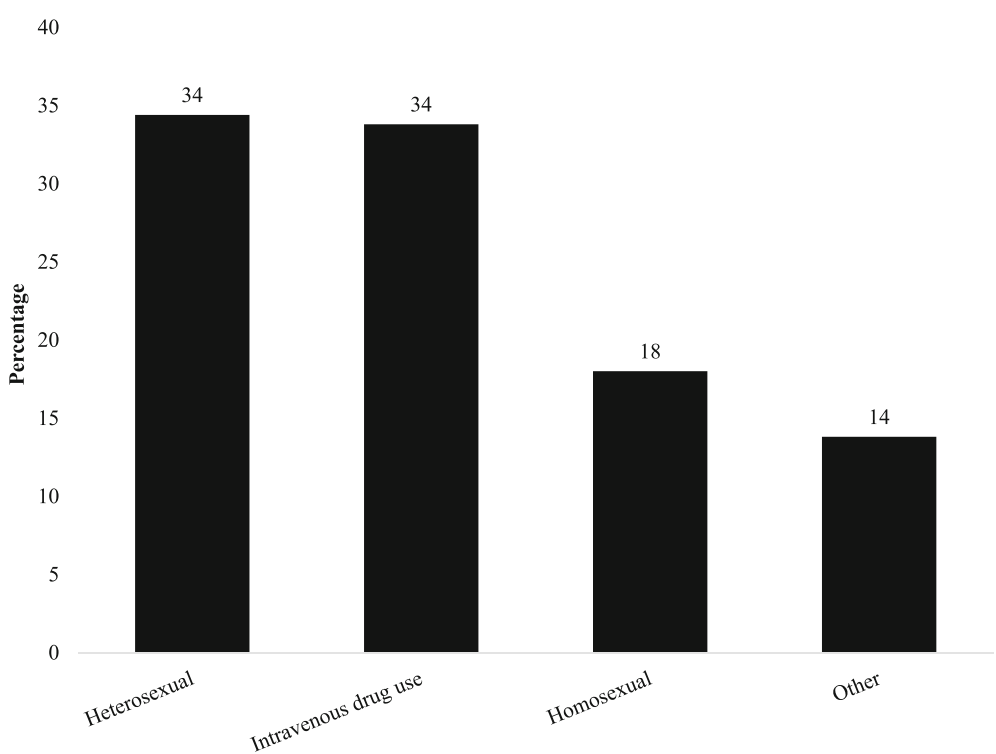

Fig. 2 Risk factor for HIV transmission among people living with HIV $(n=355)$

individuals within our study regarding risk factors for delayed initiation of HIV treatment are comparable to previous research conducted in other countries, including Brazil [21], Vietnam [6], and the United

Table 3 Reasons for delay in initiation of HIV treatment ( $n=$ 101)

\begin{tabular}{lll}
\hline Reasons & $\boldsymbol{n}$ & \% \\
\hline Felt healthy and thought the treatment was not necessary & 46 & 45.5 \\
Fear of stigma and discrimination in community & 36 & 35.6 \\
Did not have time to go to HIV treatment centre & 43 & 42.6 \\
Fear the HIV treatment is not confidential & 30 & 29.7 \\
Fear of medication side effects & 31 & 30.7 \\
Afraid of the cost / Did not have money & 26 & 25.7 \\
Fear of stigma and discrimination at facility & 25 & 24.8 \\
Did not want to take medicine for HIV & 34 & 33.7 \\
Did not know the location of HIV treatment centre & 33 & 32.7 \\
HIV treatment centre too far away & 29 & 28.7 \\
Administration and formalities are too difficult & 11 & 10.9 \\
Detention or imprisonment & 5 & 5.0 \\
Fear of detention or imprisonment & 14 & 13.9 \\
Perception of low service quality at facility & 13 & 12.9 \\
Did not want to think about being HIV-positive & 32 & 31.7 \\
Didn't believe in HIV test result & 34 & 33.7 \\
Did not want to discuss HIV result & 38 & 37.6 \\
Did not have an insurance & 7 & 6.9 \\
Moved out of town & 6 & 5.9 \\
Test not performed in the hospital providing HIV care & 31 & 30.7 \\
\hline
\end{tabular}

States of America (USA) [10]. This also applies to the presence of tuberculosis and other chronic diseases, such as hepatitis $B$ and $C$, which were associated with an HIV infection. This was also observed in our study, where a large proportion of the respondents (44.2\%) were tested for HIV after the appearance of symptoms. These findings are consistent with previous research conducted in India [12, 22].

Our study results show that the prevalence of late commencement of HIV treatment in Pakistan is about $28.5 \%$. This urgently needs to be addressed. Overall, this proportion of late onset of HIV treatment is comparable to studies conducted in Kenya [23], India [12], and the USA [10]. Previous studies from Brazil [21] and Cameroon [24] have revealed a relatively lower percentage of late onset of treatment; i.e., 9 and 15\% respectively. Furthermore, studies conducted in Ukraine [25], France [26], and Vietnam [6] showed an even higher proportion for late onset of HIV treatment (i.e. more than 45\%). The main factors associated with these high figures were: low educational attainment, non-appearance of symptoms, and not having time to go to an AIDS centre in Ukraine [25], and low levels of awareness about the disease [26], feeling healthy, and a history of intravenous drug use in Vietnam [6]. Similarly, feeling healthy, not having enough time to go to an HIV treatment centre, unwillingness to discuss HIV test results, and fear of stigma and discrimination within their community were the most frequent reasons for delayed initiation of HIV treatment in our study.

In the present study, almost half of the respondents delayed HIV treatment because they were not feeling ill. Feeling healthy and late onset of HIV-related signs and symptoms as a major factor in the delayed initiation of 
Table 4 Association between late commencement of HIV treatment and socio-demographic factors

\begin{tabular}{|c|c|c|c|c|c|}
\hline \multirow[t]{3}{*}{ Variables } & \multicolumn{2}{|c|}{ Initiation of HIV treatment } & \multirow[t]{3}{*}{ Total $n(\%)$} & \multirow[t]{3}{*}{$x^{2}$-value } & \multirow[t]{3}{*}{$P$-value } \\
\hline & Delayed $(n=101)$ & Early $(n=254)$ & & & \\
\hline & $\%$ & $\%$ & & & \\
\hline \multicolumn{6}{|l|}{ Age (in years) } \\
\hline $18-29$ & 48.5 & 44.5 & $162(45.6)$ & 2.627 & 0.269 \\
\hline $30-39$ & 28.7 & 37.4 & $124(34.9)$ & & \\
\hline 40 and above & 22.8 & 18.1 & $69(19.5)$ & & \\
\hline \multicolumn{6}{|l|}{ Gender } \\
\hline Male & 73.3 & 73.6 & $261(73.6)$ & 8.622 & 0.013 \\
\hline Female & 15.8 & 22.8 & $74(20.8)$ & & \\
\hline Transgender & 10.9 & 3.6 & $20(5.6)$ & & \\
\hline \multicolumn{6}{|l|}{ Religion } \\
\hline Muslim & 94.1 & 96.1 & $339(95.5)$ & 0.674 & 0.412 \\
\hline Christian & 5.9 & 3.9 & $16(4.5)$ & & \\
\hline \multicolumn{6}{|l|}{ District } \\
\hline Lahore & 39.6 & 49.6 & $166(46.8)$ & 2.904 & 0.088 \\
\hline Other & 60.4 & 50.4 & $189(53.2)$ & & \\
\hline \multicolumn{6}{|l|}{ Place of residence } \\
\hline Urban & 73.3 & 84.6 & $289(81.4)$ & 6.182 & 0.013 \\
\hline Rural & 26.7 & 15.4 & $66(18.6)$ & & \\
\hline \multicolumn{6}{|l|}{ Marital status } \\
\hline Unmarried & 32.7 & 33.9 & $119(33.5)$ & 0.269 & 0.992 \\
\hline Married & 61.3 & 59.8 & $214(60.3)$ & & \\
\hline Separated & 1.0 & 1.6 & $5(1.4)$ & & \\
\hline Divorced & 1.0 & 0.8 & $3(0.8)$ & & \\
\hline Widowed & 4.0 & 3.9 & $14(3.9)$ & & \\
\hline \multicolumn{6}{|l|}{ Educational level } \\
\hline No schooling & 47.5 & 26.4 & $115(32.4)$ & 20.580 & $<0.001$ \\
\hline Primary & 25.7 & 22.0 & $82(23.1)$ & & \\
\hline Secondary & 17.8 & 31.9 & 99 (27.9) & & \\
\hline College & 5.9 & 13.0 & $39(11.0)$ & & \\
\hline University & 3.1 & 6.7 & $20(5.6)$ & & \\
\hline \multicolumn{6}{|l|}{ Employment status } \\
\hline Employed & 42.6 & 58.3 & $191(53.8)$ & 7.161 & 0.007 \\
\hline Unemployed & 57.4 & 41.7 & $164(46.2)$ & & \\
\hline \multicolumn{6}{|c|}{ Type of household income } \\
\hline Permanent income & 45.5 & 65.0 & $211(59.4)$ & 11.300 & 0.001 \\
\hline Occasional income & 54.5 & 35.0 & $144(40.6)$ & & \\
\hline
\end{tabular}

HIV treatment has also been observed in a number of previous studies $[6,9,25,27,28]$. However, $42.6 \%$ of PLHIV delayed their treatment due to not having enough time to visit the HIV clinic. Previous studies have also reported that PLHIV delay their visit to an HIV treatment centre because they have heard about long, complex, and time-consuming processes at such centres, comprising of multiple appointments, numerous physical examinations, and too much time spent waiting to consult a physician $[6,25]$.

The public's negative attitudes, ideas, and viewpoints about HIV disease might explain the fact that $37.6 \%$ of our study respondents delayed their HIV treatment because they did not want to talk about their HIV-positive 
Table 5 Association between late commencement of HIV treatment and HIV and other related characteristics

\begin{tabular}{|c|c|c|c|c|c|}
\hline \multirow[t]{3}{*}{ Variables } & \multicolumn{2}{|c|}{ Initiation of HIV treatment } & \multirow{3}{*}{$\begin{array}{l}\text { Total } \\
\text { n (\%) }\end{array}$} & \multirow[t]{3}{*}{$x^{2}$-value } & \multirow[t]{3}{*}{$p$-value } \\
\hline & \multirow{2}{*}{$\begin{array}{l}\text { Delayed }(n=101) \\
\%\end{array}$} & \multirow{2}{*}{$\begin{array}{l}\text { Early } \\
(n=254) \\
\%\end{array}$} & & & \\
\hline & & & & & \\
\hline \multicolumn{6}{|l|}{ Initial CD4 count (cells/mm³) } \\
\hline$<200$ & 19.8 & 33.5 & $105(29.6)$ & \multirow[t]{3}{*}{6.652} & \multirow[t]{3}{*}{0.036} \\
\hline $200-349$ & 25.7 & 19.6 & $76(21.4)$ & & \\
\hline$>349$ & 54.5 & 46.9 & $174(49.0)$ & & \\
\hline \multicolumn{6}{|l|}{ Reason for HIV testing } \\
\hline Appearance of symptoms & 38.6 & 46.5 & $157(44.2)$ & \multirow[t]{5}{*}{6.012} & \multirow[t]{5}{*}{0.198} \\
\hline HIV positive partner & 19.8 & 20.1 & $71(20.0)$ & & \\
\hline Routine test & 31.7 & 20.0 & $83(23.4)$ & & \\
\hline Pregnancy & 4.0 & 6.3 & $20(5.7)$ & & \\
\hline Just wanted to know & 5.9 & 7.1 & $24(6.8)$ & & \\
\hline \multicolumn{6}{|c|}{ Risk factor for HIV transmission } \\
\hline Heterosexual & 28.7 & 36.6 & $122(34.4)$ & \multirow[t]{4}{*}{7.382} & \multirow[t]{4}{*}{0.061} \\
\hline Homosexual & 15.8 & 18.9 & $64(18.0)$ & & \\
\hline IDU & 44.6 & 29.5 & $120(33.8)$ & & \\
\hline Other & 10.9 & 15.0 & 49 (13.8) & & \\
\hline \multicolumn{6}{|l|}{ Physical disability } \\
\hline No & 82.2 & 82.7 & $293(82.5)$ & \multirow[t]{3}{*}{0.286} & \multirow[t]{3}{*}{0.958} \\
\hline Pre-HIV & 2.0 & 2.3 & $8(2.3)$ & & \\
\hline Post-HIV & 15.8 & 15.0 & $54(15.2)$ & & \\
\hline \multicolumn{6}{|c|}{ Any associated chronic disease } \\
\hline Tuberculosis & 14.9 & 15.7 & $55(15.5)$ & \multirow[t]{6}{*}{8.209} & \multirow[t]{6}{*}{0.145} \\
\hline Diabetes & 3.0 & 2.0 & $8(2.3)$ & & \\
\hline Hypertension & 1.0 & 1.2 & $4(1.1)$ & & \\
\hline Hepatitis B & 5.0 & 0.8 & $7(2.0)$ & & \\
\hline Hepatitis C & 26.7 & 22.4 & $84(23.7)$ & & \\
\hline None & 49.4 & 57.9 & $197(55.5)$ & & \\
\hline
\end{tabular}

test result. This is even further reinforced by the fear of stigma and discrimination within their community. Our findings were similar to those of previous research in countries like Zimbabwe [29], Brazil [21], Lao People's Democratic Republic [27], and Vietnam [6, 30, 31], where PLHIV perceived that, after starting HIV treatment, their HIV-positive result would become known to their relatives.

Our study's findings, after applying multivariable logistic regression, revealed that rural residence and living in a district other than Lahore were significantly associated with late onset of HIV treatment. People living in rural areas and districts other than Lahore have less awareness about HIV, lower educational status, and more difficulties in visiting HIV management centres, which are situated far away from their homes, due to transport problems and cost issues [12, 32]. In developing countries like Pakistan, HIV treatment coverage is low as only 24,362 PLHIV out of 190,000 cases are receiving ART in 49 treatment centres situated in different parts of the country, particularly in big cities $[33,34]$. The low healthcare coverage for HIV results in late diagnosis, poor linkages with healthcare facilities, and consequently delayed onset of ART [33, 34]. Like other developing countries, there is a need to initiate $\mathrm{U}=\mathrm{U}$ campaigns (undetectable equals untransmissible) to develop awareness that PLHIV who adhere strictly to ART have undetectable level of virus in their blood and so are very unlikely to transmit it to others [7].

This study also indicates that illiteracy is also related to late commencement of HIV treatment, which is in accordance with prior studies $[4,12,25,27,35]$. This could be because illiterate patients have less knowledge about HIV, including risk factors, detection, prevention, 
Table 6 Association between socio-demographic and HIV related factors and delayed onset of HIV treatment among HIV patients

\begin{tabular}{|c|c|c|c|c|c|c|c|c|}
\hline \multirow[t]{2}{*}{ Variables } & \multirow[t]{2}{*}{$\mathrm{OR}^{\mathrm{a}}$} & \multicolumn{2}{|c|}{$95 \% \mathrm{Cl}$} & \multirow[t]{2}{*}{$P$-value } & \multirow[t]{2}{*}{$A^{\prime} R^{b}$} & \multicolumn{2}{|c|}{$95 \% \mathrm{Cl}$} & \multirow[t]{2}{*}{$P$-value } \\
\hline & & Lower & Upper & & & Lower & Upper & \\
\hline \multicolumn{9}{|l|}{ District } \\
\hline Lahore & 0.666 & 0.417 & 1.064 & 0.089 & 0.518 & 0.308 & 0.872 & 0.013 \\
\hline Other & 1 & & & & 1 & & & \\
\hline \multicolumn{9}{|l|}{ Place of residence } \\
\hline Urban & 0.497 & 0.285 & 0.868 & 0.014 & 0.446 & 0.239 & 0.831 & 0.011 \\
\hline Rural & 1 & & & & 1 & & & \\
\hline \multicolumn{9}{|l|}{ Educational level } \\
\hline No schooling & 4.060 & 1.126 & 14.632 & 0.032 & 5.916 & 1.378 & 25.408 & 0.017 \\
\hline Primary & 2.631 & 0.708 & 9.776 & 0.149 & 3.576 & 0.881 & 14.519 & 0.075 \\
\hline Secondary & 1.259 & 0.333 & 4.758 & 0.734 & 1.609 & 0.401 & 6.447 & 0.502 \\
\hline College & 1.030 & 0.229 & 4.638 & 0.969 & 1.329 & 0.272 & 6.488 & 0.725 \\
\hline University & 1 & & & & 1 & & & \\
\hline \multicolumn{9}{|l|}{ Employment status } \\
\hline Employed & 1 & & & & 1 & & & \\
\hline Unemployed & 1.883 & 1.181 & 3.003 & 0.008 & 0.257 & 0.062 & 1.065 & 0.061 \\
\hline \multicolumn{9}{|c|}{ Type of household income } \\
\hline Permanent income & 1 & & & & 1 & & & \\
\hline Occasional income & 2.217 & 1.387 & 3.542 & 0.001 & 3.885 & 1.014 & 14.889 & 0.048 \\
\hline \multicolumn{9}{|l|}{$\begin{array}{l}\text { Initial CD4 count } \\
(\text { cells } / \mathrm{mm})^{3}\end{array}$} \\
\hline$<200$ & 0.509 & 0.284 & 0.912 & 0.023 & 0.479 & 0.248 & 0.925 & 0.028 \\
\hline $200-349$ & 1.125 & 0.635 & 1.993 & 0.686 & 1.326 & 0.707 & 2.486 & 0.380 \\
\hline$>349$ & 1 & & & & 1 & & & \\
\hline \multicolumn{9}{|l|}{ Reason for HIV testing } \\
\hline Symptoms & 0.992 & 0.368 & 2.675 & 0.987 & 0.900 & 0.302 & 2.684 & 0.849 \\
\hline HIV-positive partner & 1.176 & 0.408 & 3.392 & 0.764 & 1.255 & 0.393 & 4.007 & 0.702 \\
\hline Routine offer & 1.882 & 0.676 & 5.242 & 0.196 & 2.281 & 0.742 & 7.008 & 0.150 \\
\hline Pregnancy & 0.750 & 0.179 & 3.144 & 0.694 & 0.692 & 0.143 & 3.351 & 0.647 \\
\hline Just wanted to know & 1 & & & & 1 & & & \\
\hline \multicolumn{9}{|c|}{ Any associated chronic disease } \\
\hline Present & 1.401 & 0.882 & 2.226 & 0.153 & 1.590 & 0.949 & 2.665 & 0.078 \\
\hline Absent & 1 & & & & 1 & & & \\
\hline
\end{tabular}

$1=$ reference category

${ }^{a} O R$ Odds ratio

${ }^{\mathrm{b}} A O R$ Adjusted odds ratio. Results obtained from final model after applying backward stepwise multivariable logistic regression

management, and prognosis. They have less contact with print media, less involvement in HIV-related workshops, and less communication with other people.

Our study also found an association between CD4 count and late onset of HIV treatment. The relationship between delayed onset of HIV treatment and high CD4 count can be explained by the fact that many asymptomatic PLHIV feel themselves to be healthy. As a result, they suppose that they can delay HIV treatment until the emergence of symptoms [24]. In addition to social factors, awareness and implementation of the WHO guidelines regarding HIV treatment are very important for timely initiation of ART. Initiation of ART, irrespective of CD4 count, is not only important for reducing HIV transmission but also significant for PLHIV who have poor access to services and high loss to follow-up after diagnosis [13]. However, in Pakistan, the new guidelines are still not being followed. There is a need to adopt the WHO's new guidelines on the timing of onset of HIV treatment [13, 14]. 
Furthermore, in the present study, occasional household income was related to delayed onset of ART. Similar results are seen in previous studies conducted in the USA [10, 36] and India [12]. Patients with fewer financial resources spend less money on their treatment, such as paying for medicines and regular visits to their HIV management centre. PLHIV with low socio-economic status usually seek healthcare from government hospitals. Previous research has also highlighted that PLHIV diagnosed at government testing centres or health facilities were more likely to present late for HIV care than those diagnosed at a private hospital [34]. People with low socio-economic status are less likely to receive HIV testing and care from private facilities due to the high cost, so they only engage in care when they develop symptoms [34]. Additionally, not all HIV/AIDS-related health services are available in government facilities in Pakistan and patients need to pay out of their own pockets for some services [15, 33]. Pakistan lacks a health insurance system, which has also resulted in low engagement with HIV care and late initiation of ART [34].

\section{Limitations and strengths}

Our research findings cannot be applied to the entire Pakistani population because we only included those HIV-positive individuals who came to visit HIV clinics in selected hospitals in Lahore for HIV treatment. Our research questionnaire does not include details about factors like self-medication or the nature of a participant's occupation, although this is presumably associated with late onset of HIV treatment. A sufficiently large sample size has been included, which helped in controlling the confounders and also identified potential risk factors for delayed onset of HIV treatment. Despite these limitations, our study has considerable strengths. Faceto-face interviews were carried out by the first author himself to collect the data, therefore an improved quality data was collected for this study.

\section{Conclusions}

Our study results show that delayed onset of HIV treatment in Pakistan is common. Factors such as occasional household income and no schooling were significantly correlated with delayed initiation of ART. The main reasons for the late onset of HIV treatment were feeling healthy and not having symptoms, not having time to go to an HIV treatment centre, lack of willingness to discuss their HIV test result, and fear of stigma and discrimination within their community.

An integrated, multidisciplinary, comprehensive, and patient-focused approach is needed to promote the welltimed initiation of HIV treatment in order to reduce both HIV transmission and mortality. HIV management centres should counsel and monitor patients from the time of a positive HIV test result until they initiate treatment.

\section{Abbreviations}

AIDS: Acquired immunodeficiency syndrome; AOR: Adjusted odds ratio; ART: Anti-retroviral treatment; CD4: Cluster of differentiation 4; CDC: Centers for Disease Control and Prevention; Cl: Confidence interval; FSW: Female sex worker; HIV: Human immunodeficiency virus; IDU: Intravenous drug user; Lao PDR: Lao People's Democratic Republic; MSW: Male sex worker; P\&SHD: Primary and Secondary Healthcare Department; PACP: Punjab AIDS Control Program; PCR: Polymerase chain reaction; SD: Standard deviation; SPSS: Statistical package for social sciences; USA: United States of America

\section{Supplementary Information}

The online version contains supplementary material available at https://doi. org/10.1186/s12889-021-11031-0 .

Additional file 1. Questionnaire.

\section{Acknowledgements}

The authors thank the Project Director and respected staff members of Punjab AIDS Control Program (PACP), Primary and Secondary Healthcare Department (P\&SHD), Lahore, Pakistan for their guidance and help to complete this study. The authors also gratefully acknowledge the honorable administration and respected staff members of HIV clinics of selected hospitals of Lahore, Pakistan for their support during this research work. In addition, the authors express their gratitude to the study respondents, without whom this study would not be possible.

This paper is dedicated to the memory of Dr. Hasan Ali who passed suddenly away after submission of the manuscript.

\section{Authors' contributions}

HA conceptualized and conducted the research, collected and analyzed the data, interpreted the findings, and wrote the manuscript. RZ designed and supervised the study and reviewed the manuscript. KJ and FF interpreted and provided input for preparing the manuscript. AK, RZ and FF critically reviewed the manuscript and provided feedback for important intellectual content. All authors read and approved the final manuscript.

\section{Funding}

The study was funded by the Punjab AIDS Control Program (PACP), Primary and Secondary Healthcare Department (P\&SHD), Government of the Punjab, Lahore, Pakistan.

We acknowledge support from the German Research Foundation (DFG) and the Open Access Publication Fund of Charité - Universitätsmedizin Berlin. Open Access funding enabled and organized by Projekt DEAL.

Availability of data and materials

The data is available from the corresponding author upon on reasonable request.

\section{Declarations}

Ethics approval and consent to participate

Ethical approval was taken from Institutional Ethics Review Board, University of the Punjab, Lahore (Ref No: 1125/IERB/PU). In addition, approvals for data collection were obtained from HIV clinics of selected hospitals of Lahore as well as from the project director of Punjab AIDS Control Program (PACP/Admin/ 24786), Primary and Secondary Healthcare Department (P\&SHD), Government of the Punjab, Lahore, Pakistan. Confidentiality, anonymity, and privacy of all study respondents was guaranteed at all levels in this study. No identifying information of the patient such as name, date of birth, telephone number, or address was recorded. Informed consent was taken from all subjects. The aim of research was explained to the patients in detail. Patients were also informed about the possible risks/discomfort involved. Data collection process was carried out in a comfortable environment where patients had the opportunity to speak openly and they also had the right to ask any question about the study. All methods were carried out in accordance with the "Guidelines and 
Recommendations to Assure Good Epidemiologic Practice" developed by the German Society for Epidemiology [13].

\section{Consent for publication}

Not applicable.

\section{Competing interests}

The authors declare that they have no competing interests. FF serves as Academic Editor for BMC Public Health.

\section{Author details}

'Department of Public Health, Institute of Social and Cultural Studies, University of the Punjab, Lahore, Pakistan. ${ }^{2}$ Department of Public Health, The University of Haripur, Haripur, Pakistan. ${ }^{3}$ Institute of Public Health, Charité, Universitätsmedizin Berlin, Charitéplatz 1, 10117 Berlin, Germany. ${ }^{4}$ Institute of Gerontological Health Services and Nursing Research,

Ravensburg-Weingarten University of Applied Sciences, Weingarten, Germany.

\section{Received: 9 November 2020 Accepted: 10 May 2021}

Published online: 27 May 2021

\section{References}

1. Global statistics: The global HIV/AIDS epidemic. 2019. Available online: https://www.hiv.gov/hiv-basics/overview/data-and-trends/global-statistics. Accessed 25 Oct 2020

2. Joint United Nations Programme on HIV/AIDS: AIDS info data sheet Pakistan. 2019. Available online: http://aidsinfo.unaids.org. Accessed 25 Oct 2020.

3. Siddiqui $\mathrm{MH}$, Siddiqui JA, Ahmed I. Demographic profile and clinical features of admitted HIV patients in a tertiary care teaching hospital of Karachi, Pakistan. Pak J Med Sci. 2009;25(5):861-4.

4. Altaf A, Agha A, McKinzie MH, Abbas Q, Jafri SB, Emmanuel F. Size estimation, HIV prevalence and risk behaviours of female sex workers in Pakistan. J Pak Med Assoc. 2012;62(6):551-7.

5. Khan AA, Khan A, Bokhari A. The HIV epidemic in Pakistan. J Pak Med Assoc. 2010;60(4):300-7.

6. Rangarajan S, Tram HN, Todd CS, Thinh T, Hung V, Hieu PT, Hanh TM, Chau KM, Lam ND, Hung PT West G, Colby D. Risk factors for delayed entrance into care after diagnosis among patients with late-stage HIV disease in southern Vietnam. PLoS One. 2014;9(10):e108939. https://doi.org/10.1371/ journal.pone.0108939.

7. Tobin SC. $U=U$ gains strength with release of PARTNER2 data. AIDS. 2019; 33(3):N1. https://doi.org/10.1097/QAD.0000000000002098.

8. Ingabire PM, Semitala F, Kamya MR, Nakanjako D. Delayed antiretroviral therapy (ART) initiation among hospitalized adults in a resource-limited setting: a challenge to the global target of ART for $90 \%$ of HIV-infected individuals. AIDS Res Treat. 2019;2019:1832152. https://doi.org/10.1155/201 9/1832152.

9. Jenness SM, Myers JE, Neaigus A, Lulek J, Navejas M, Raj-Singh S. Delayed entry into HIV medical care after HIV diagnosis: risk factors and research methods. AIDS Care. 2012;24(10):1240-8. https://doi.org/10.1080/09540121.2 012.656569

10. Bamford LP, Ehrenkranz PD, Eberhart MG, Shpaner M, Brady KA. Factors associated with delayed entry into primary HIV medical care after HIV diagnosis. AIDS. 2010;24(6):928-30. https://doi.org/10.1097/QAD.0b013e32 $8337 \mathrm{~b} 116$

11. Herout S, Mandorfer M, Breitenecker F, Reiberger T, GrabmeierPfistershammer K, Rieger A, Aichelburg MC. Impact of early initiation of antiretroviral therapy in patients with acute HIV infection in Vienna, Austria. PLoS One. 2016;11(4):e0152910. https://doi.org/10.1371/journal.pone.015291 0.

12. Alvarez-Uria G. Factors associated with delayed entry into HIV medical care after HIV diagnosis in a resource-limited setting: data from a cohort study in India. Peer J. 2013;1:e90. https://doi.org/10.7717/peerj.90.

13. World Health Organization. Consolidated guidelines on HIV prevention, diagnosis, treatment and care for key populations. Geneva: World Health Organization; 2016.

14. The National AIDS Control Program, Ministry of Health Government of Pakistan. Guidelines for the use of antiretroviral therapy in hiv positive adults and adolescents in Pakistan. Islamabad: NAIDSCP: 2005.

15. Altaf A. Is Pakistan at the cusp of an ART resistance? JPMA. 2020;70(11):2046-7.
16. Emmanuel F, Salim M, Akhtar N, Arshad S, Reza TE. Second-generation surveillance for HIV/AIDS in Pakistan: Results from the 4th round of Integrated Behavior and Biological Survey 2011-2012. Sex Transm Infect. 2013:89(3):iii23-8.

17. Daniel WW, Cross CL. Biostatistics: a foundation for analysis in the health sciences. New York: Wiley; 2013.

18. Centers for Disease Control and Prevention: CDC HIV prevention strategic plan; extended through 2010. 2007. Available online: https://stacks.cdc.gov/ view/cdc/5518. Accessed 25 Oct 2020.

19. Moreira A, Fronteira I, Augusto G, Martins M. Unmatched case-control study on late presentation of HIV infection in Santiago, Cape Verde (2004-2011). Int J Environ Res Public Health. 2016;13(3):320. https://doi.org/10.3390/ ijerph13030320

20. Hosmer DW Jr, Lemeshow S, Sturdivant RX. Applied logistic regression. New York: Wiley; 2013. https://doi.org/10.1002/9781118548387.

21. MacCarthy S, Hoffmann M, Nunn A, Silva LA, Dourado I. Barriers to HIV testing, linkage to care, and treatment adherence: a cross-sectional study from a large urban center of Brazil. Pan Am J Public Health. 2016;40(6):418-26.

22. Pati S, Bhattacharya S, Swain S. Prevalence and patterns of multimorbidity among human immunodeficiency virus positive people in Odisha, India: an exploratory study. J Clin Diagn Res. 2017;11(6):LC10-3. https://doi.org/10. 7860/JCDR/2017/22766.10014

23. Kwobah CM, Braitstein P, Koech JK, Simiyu G, Mwangi AW, Wools-Kaloustian K, Siika AM. Factors associated with late engagement to HIV care in Western Kenya: a cross-sectional study. J Int Assoc Provid AIDS Care. 2016;15(6):50511. https://doi.org/10.1177/2325957414567682.

24. Takah NF, Awungafac G, Aminde LN, Ali I, Ndasi J, Njukeng P. Delayed entry into HIV care after diagnosis in two specialized care and treatment centres in Cameroon: the influence of CD4 count and WHO staging. BMC Public Health. 2016;16:529. https://doi.org/10.1186/s12889-016-3258-8.

25. Neduzhko O, Postnov O, Perehinets I, DeHovitz J, Joseph M, Odegaard D, Kaplan R, Kiriazova T. Factors associated with delayed enrollment in HIV medical care among HIV-positive individuals in Odessa region, Ukraine. J Int Assoc Provid AIDS Care. 2017;16(2):168-73. https://doi.org/10.1177/232 5957416686194

26. Wilson KD, Dray-Spira R, Aubrière C, Hamelin C, Spire B, Lert F. ANRS-VESPA2 study group. Frequency and correlates of late presentation for HIV infection in France: older adults are a risk group-results from the ANRS-VESPA2 study, France. AIDS Care. 2014;26(1):S83-93. https://doi.org/10.1080/09540121.2014.906554.

27. Chanvilay T, Yoshida Y, Reyer JA, Hamajima N. Factors associated with access to antiretroviral treatment among people living with HIV in Vientiane capital, Lao PDR. Nagoya J Med Sci. 2015;77(1-2):29-39.

28. Thanawuth N, Chongsuvivatwong V. Late HIV diagnosis and delay in CD4 count measurement among HIV-infected patients in southern Thailand. AIDS Care. 2008;20(1):43-50. https://doi.org/10.1080/09540120701439303.

29. Nyika H, Mugurungi O, Shambira G, Gombe NT, Bangure D, Tshimanga M. Factors associated with late presentation for HIV/AIDS care in Harare city, Zimbabwe, 2015. BMC Public Health. 2016;16:369. https://doi.org/10.1186/ s12889-016-3044-7.

30. Tran DA, Shakeshaft A, Ngo AD, Rule J, Wilson DP, Zhang L, Doran C. Structural barriers to timely initiation of antiretroviral treatment in Vietnam: findings from six outpatient clinics. PLoS One. 2012;7(12):e5E1289. https:// doi.org/10.1371/journal.pone.0051289.

31. Thi MD, Brickley DB, Vinh DT, Colby DJ, Sohn AH, Trung NQ, Giang LT, Mandel JS. A qualitative study of stigma and discrimination against people living with HIV in Ho Chi Minh City, Vietnam. AIDS Behav. 2008;12(1):63-70. https://doi.org/10.1007/s10461-008-9374-4.

32. Losina E, Bassett IV, Giddy J, Chetty S, Regan S, Walensky RP, Ross D, Scott CA, Uhler LM, Kath JN, Holst H, Freedberg KA. The "ART" of linkage: pretreatment loss to care after HIV diagnosis at two PEPFAR sites in Durban, South Africa. PloS One. 2010;5(3):e9538. https://doi.org/10.1371/journal.pone. 0009538.

33. Arif F. HIV crisis in Sindh, Pakistan: the tip of the iceberg. Lancet Infect Dis. 2019;19(7):695-6. https://doi.org/10.1016/S1473-3099(19)30265-8.

34. Koirala S, Deuba K, Nampaisan O, Marrone G, Ekström AM, CAT-S group. Facilitators and barriers for retention in HIV care between testing and treatment in Asia-A study in Bangladesh, Indonesia, Lao, Nepal, Pakistan, Philippines and Vietnam. PLoS One. 2017;12(5):e0176914. https://doi.org/1 0.1371/journal.pone.0176914.

35. Vigneshwaran E, Padmanabhareddy Y, Devanna N, Alvarez-Uria G. Gender differences in health related quality of life of people living with HIV/AIDS in 
the era of highly active antiretroviral treatment. N Am J Med Sci. 2013;5(2): 102-7. https://doi.org/10.4103/1947-2714.107526.

36. Arnold EA, Weeks J, Benjamin M, Stewart WR, Pollack LM, Kegeles SM, et al. Identifying social and economic barriers to regular care and treatment for black men who have sex with men and women (BMSMW) and who are living with HIV: a qualitative study from the Bruthas cohort. BMC Health Serv Res. 2017;17:90. https://doi.org/10.1186/s12913-017-2011-z.

\section{Publisher's Note}

Springer Nature remains neutral with regard to jurisdictional claims in published maps and institutional affiliations.

Ready to submit your research? Choose BMC and benefit from:

- fast, convenient online submission

- thorough peer review by experienced researchers in your field

- rapid publication on acceptance

- support for research data, including large and complex data types

- gold Open Access which fosters wider collaboration and increased citations

- maximum visibility for your research: over $100 \mathrm{M}$ website views per year

At $\mathrm{BMC}$, research is always in progress.

Learn more biomedcentral.com/submissions 